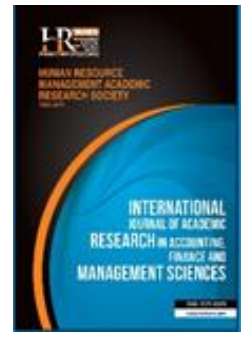

International Journal of Academic Research in Accounting, Finance and Management Sciences

Vol. 8, No.3, July 2018, pp. 141-148

E-ISSN: 2225-8329, P-ISSN: 2308-0337

(c) 2018 HRMARS

www.hrmars.com

To cite this article: Peprah, W.K. (2018). Predictive Relationships among the Elements of the Fraud Diamond Theory: The Perspective of Accountants, International Journal of Academic Research in Accounting, Finance and Management Sciences 8 (3): 141-148.

\title{
Predictive Relationships among the Elements of the Fraud Diamond Theory: The Perspective of Accountants
}

\author{
Williams Kwasi PEPRAH
}

School of Business, Valley View University, Oyibi, Accra-Ghana, E-mail: williams.peprah@vvu.edu.gh

\begin{abstract}
This study researched the predictive relationships among the elements of fraud diamond theory and how accountants rank these relationships for early detection of fraud. A ranking Likert scale questionnaire on the four elements of Pressure/incentive, opportunity, rationalization, and capability were randomly distributed and answered by 100 accountants who are members of the Institute of Chartered Accountants, Ghana. Based on Spearmen's rank order correlation, positive linear relationships were found to exist among all the four elements of the fraud diamond theory. Regarding predictive ranking of fraud occurrences from the perspective of accountants, the study noted that in order from large to small these probabilities are: Capability/Opportunity 0.611, Capability/Rationalization 0.574, Pressure/Rationalization 0.518, Opportunity/Rationalization 0.463, Capability/Pressure 0.266 and Pressure/Opportunity 0.212. Capability/Opportunity, Capability/Rationalization, and Pressure/Rationalization give a large prediction of fraud happening; Opportunity/Rationalization gives a medium prediction and Capability/Pressure, and Pressure/Opportunity provide a small prediction. The study, therefore, concluded that when the opportunity is minimized, potential fraudsters' capability can be rendered redundant through supervision and when rationalization is made difficult, potential fraudsters delay or avoid their act of fraud. Policy-makers should, therefore, consider policies that reduce the opportunity to commit fraud and rationalization should be given much attention. Effective supervision must be intensified to control capability.
\end{abstract}

Key words Fraud Diamond Theory, Fraud Triangle Theory, pressure, opportunity, rationalization, capability, fraud, Financial Statement Fraud

Received: 17 Aug 2018 (C) The Authors 2018

Revised: 08 Sept 2018 Published by Human Resource Management Academic Research Society (www.hrmars.com

Accepted: 20 Sept 2018 This article is published under the Creative Commons Attribution (CC BY 4.0) license. Anyone may Published Online: 29 Sept 2018 reproduce, distribute, translate and create derivative works of this article (for both commercial and noncommercial purposes), subject to full attribution to the original publication and authors. The full terms of this license may be seen at: http://creativecommons.org/licences/by/4.0/legalcode

\section{Introduction}

Our world today is witnessing a lot of fraudulent activities in business. All economies have been affected by financial frauds, and they are threats to the survival and growth of all businesses hence there is the need to prevent and detect these frauds (Ocansey, 2017; Ocansey et al., 2015). Abdullahi et al. (2015) posit that the detection of these frauds at the initial stage is less costly and efficient than after they occur. In 1953, Cressey came out with his fraud triangle theory after understudying the white-collar crime theory by Sutherland in 1939 to help detect fraud at the early stage. As the years went by people became more knowledgeable in fraudulent activities, and as a result, Wolfe and Hermanson (2004) came out with one additional element to develop the fraud diamond theory.

The fraud triangle theory consists of three elements: opportunity, rationalization, and pressure (Cressey, 1953). Wolfe and Hermanson (2004) added the capability to the elements to make it a diamond shape. This transformation from fraud triangle theory to fraud diamond theory has been noted by Mackevicius and Giriunas (2013) to scale measure fraud base on condition, motive, fulfillment, and 
capabilities. Ocansey and Ganu (2017) also explained that a potential fraudster might have the pressure, opportunity, and rationalization to commit fraud but he or she cannot commit fraud when there is lack of capability. The accounting profession has been observed to encounter a lot of fraudulent activities, and in effect, they are noted for aiding the prevention of and detection of financial statement fraud (Popoola et al., 2016).

Kennedy (2012) has indicated that financial statement fraud types include financial fraud and misappropriation of assets. Financial fraud relates to stealing a firm's property whether physical in nature or monetary. Misrepresentation of financial statement is also known as 'cooking the book' or manipulation of the figures to achieve desirable results. The early detection of these fraudulent activities is based on simulating the elements of the fraud diamond theory to happenings in and around the business and employees. Wolfe and Hermanson (2004) graphic presentation of the fraud diamond theory shows how the elements of opportunity, pressure/incentive, rationalization, and capability relate to each other linearly. In a recent study by Huber (2017) realized that the fraud theory was considered to show a geometrical relationship and must factor a numerical dimension to be able to explain, predict or detect fraud. According to Nijenhus (2016), there is a probability of fraud occurring, and as a result, there should be a statistical way of preventing and detecting fraud. Though this study touches on related issues of fraud diamond theory, studies incorporating these findings into the accounting profession have been found by the researcher to be non-existent. In light of this that the current study examines the predictive relationships that exist statistically among the fraud diamond elements to understand the probability of early detection of fraud among accountants. The likelihood of fraud detection is assessed by fraud diamond theory model (Zaki, 2017). Therefore the core of this study centers on the following questions:

1. What is the statistical relationship between the elements of fraud diamond theory?

2. How does one predict the probability of fraud happening among accountants based on the fraud diamond theory?

In other words, the objective of the study seeks to:

1. Determine the relationship between the elements of the fraud diamond theory.

2. Establish ranking relationships which give a predictive signal of fraud happening from the perspective of accountants.

\section{Literature Review}

According to Gilbert (1997), fraud is "an act using deceit such as intentional distortion of the truth of misrepresentation or concealment of a material fact to gain an unfair advantage over another to secure something of value or deprive another of a right" p. 124. Stephen (1883) also asserted that fraud is deceit or intention to deceive that will result in a risk of possible injury. The sequential occurrence of fraud as contended by Ruankaew (2016) is pressure/incentive, opportunity, rationalization, and capability. Pressure/incentive draws persons to look for an opportunity or the doorway and based on rationalizing the circumstances or situation a capable functionary commit fraud.

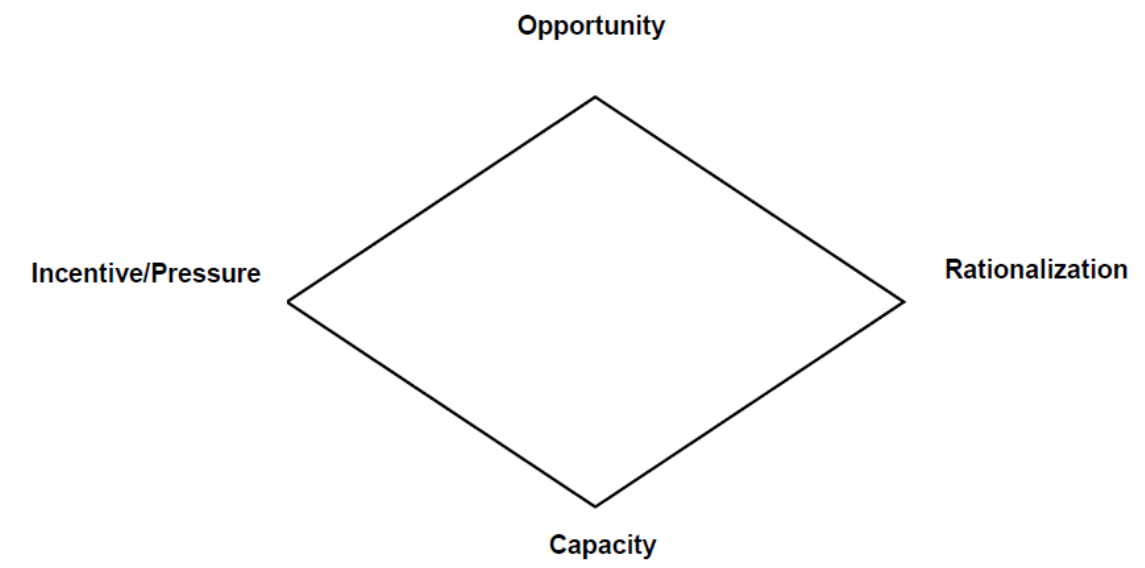

Figure 1. The fraud diamond

Source: Wolfe and Hermanson (2004) 
The elements of figure 1 are discussed below.

\subsection{Pressure/Incentive}

The pressure/incentive that induces fraud according to Rasha and Andrews (2012) can be in the form of personal, corporate or employment pressure and external pressure. On the individual level, fraud can be financial or non-financial pressure (Gbegi and Adebisi, 2013). The economic pressure relates to the lifestyle of the person, and the non-financial pressure is linked to greed and lack of financial discipline. On the corporate level, supervisors or colleagues may require some manipulation of figures, policies, and guidelines to meet a specific need.

\subsection{Opportunity}

Opportunity is the lack of structure and governance to control the operations and assets usage of the firm. Internal control weakness has been identified as the primary mechanism that gives the opportunity for fraud to occur (Ruankaew, 2016). In other to address this, Holtfreter (2004) noted that each firm should have proper organizational structure, operational and internal control steps in conjunction with prescreening of employees to know their motive.

\subsection{Rationalization}

Rationalization is the justification given for a fraudulent act with the view of overcoming competition or making a profit (Wuerges and Borba, 2013). It is the excuse that an individual gives to support the acceptance of committing fraud. In accounting, mostly the accrual concept has been noted by auditors to be a rationalization basis for providing excuses or explain or allow fraudulent act (Skousen and Wright, 2006).

\subsection{Capability}

According to Wolfe and Hermanson (2004), capability addresses the issue of the skill; knowledge, confidence, and position the individual have to commit fraud. The capability is linked to the intellect and the authoritative role the person in position has to exploit internal weakness amidst pressure with rationalization (Abdullahi et al. (2015). Shelton (2014) mentioned capability supporting qualities like intelligence, coercion, positioning, ego, stress management, and deceit. Therefore Ocansey (2017) explained that the commitment of fraud could be encouraged or discouraged by the capability and personality trait of a person. It is because the capability is what is needed to identify loophole to commit fraud.

\subsection{Empirical Review}

Puspasari (2016) study of fraud theory evolution indicated that the elements of the fraud diamond theory could be grouped into observable and non-observable. Rationalization element was considered nonobservable as it relates to what goes on in a perpetrators mind. Capability and opportunity elements were classified as observable whereas pressure is regarded as both observable and non-observable. The study concluded that the fraud diamond theory is among the modern techniques in analyzing, detecting and preventing the possibility of fraud occurring in the future.

In a study by Wong and Venkatraman (2015) asserted that business intelligence must be used in the detection of financial accounting fraud. Business intelligence is based on mining accounting data through ratio analysis and investigating the trends to determine the anomalies. This approach is based on historical data. It does not support early detection of fraud. However, it is a proactive model for identifying, clarifying and evaluating financial fraud in a firm.

Apolinar et al. (2015) also used artificial intelligence to study early detection and minimizing of financial statement fraud, to predict or forecast the occurrence of fraud. Applying logistic regression to analyzing the financial data of sampled firms concluded that the artificial intelligence element of the neural network is the most accurate method for predicting fraudulent financial statement. The financial ratios that 
supported the predictive model were current ratio, total asset turnover, debt to asset ratio and a current asset to total asset ratio.

A study among Malaysian external auditors, internal auditors and government auditors in ranking the factors of fraud diamond theory noted that external auditors ranked capability as the highest while internal auditors and government auditors ranked opportunity as the highest (Omar and Mohamad, 2010). The fraud diamond model was examined on the list of A1240, and SAS 99 and it concluded that the four dimensions of pressure, opportunity, rationalization, and capability are red flag detection of financial fraud. Contrary to these findings, Dorminey et al. (2010) have asserted that opportunity is only needed for fraud to occur. Yogo (2016) research has collaborated on this assertion that opportunity is the highest motivating factor for the occurrence of financial statement fraud.

In Nigeria, a study by Enofe et al. (2016) placed employee capability on top for fraud prevention and early detection. Using the fraud diamond theory, the study concluded that there exists a significant relationship between employees' capability and staff integrity for fraud transaction and prevention. They recommended a stricter internal control mechanism; stiffer punishment for fraud perpetrators in the Nigerian public sector.

According to Asare et al. (2015) fraud detection is the duty of accountants, and they mostly rely on rationalization in detecting financial fraud. Rationalization is based on misrepresentation of financial materials. This is confirmed by Tsegba and Upaa (2015) research that in developing countries financial statement fraud affects public confidence in auditing and accounting processes that lead to loss of jobs drop in market capitalization and criminal precaution. This research work is to assist in early detection of financial fraud based on the relationship between the fraud diamond theory elements and predict with a probable ranking of how each relationship must be examined.

\section{Methodology of research}

This research is a correlational study using the Spearman rank order correlation to establish the arbitrary monotonic and the strength of relationship among the elements of the fraud diamond theory without making any assumptions based on the frequency distribution of these elements (Hauke and Kossowski, 2011). A scale-Likert questionnaire answered by 100 accountants randomly sampled to rank how they rate the likelihood of fraud happening based on Pressure/incentive, opportunity, rationalization, and capability. According to Mohamed, Ahmad and Jon (2015) accountants have noted that financial statement fraud erodes public confidence. The Likert scale was $1=$ strongly disagree, $2=$ Disagree, $3=$ Neutral, $4=$ Agree and $5=$ Strongly Agree. These accountants are members of Institute of Chartered Accountants, Ghana. IBM SPSS 2.0 is used to calculate the spearmen's correlation. The Spearman ranked order correlation is interpreted based on Cohen (1988) guidelines of rho in respective of the negative or positive relationship:

Table 1. Spearman ranked order correlation and their interpretations

\begin{tabular}{|c|c|}
\hline Spearman rank order correlation & Interpretation \\
\hline$r=0.10$ to 0.29 & Small \\
\hline$r=0.30$ to 0.49 & Medium \\
\hline$r=0.50$ to 1.0 & Large \\
\hline
\end{tabular}

In gathering the data, none of the respondents was asked to provide any demographical information. The respondents were asked not to indicate their place of work to protect the integrity of the respondents and also not to construe that they are engaged in any fraudulent activities by ranking the elements of fraud diamond theory.

\section{Discussion of Results}

Correlation is a measure of strength or weakness between two variables ranging from -1 to +1 (Rebekic et al., 2015). The results of the Spearman's correlation indicated that there was a positive linear relationship among all the elements of the fraud diamond theory within the acceptance significance levels of $p=0.05$ and $p=0.01$ as shown in figure 2 . 
Figure 2. Spearman's rho Correlations

\begin{tabular}{|c|c|c|c|c|c|}
\hline & & $\begin{array}{l}\text { PRESSURE/IN } \\
\text { CENTIVE }\end{array}$ & OPPORTUNITY & CAPABILIT & RATIONALIZATION \\
\hline \multirow{7}{*}{$\begin{array}{l}\text { Spearman's OPPORTUNITY } \\
\text { rho }\end{array}$} & Correlation Coefficient & 1.000 & $.212^{*}$ & $.266^{* *}$ & $.518^{* *}$ \\
\hline & Sig. (2-tailed) & . & .034 & .008 & .000 \\
\hline & $\mathrm{N}$ & 100 & 100 & 100 & 100 \\
\hline & Correlation Coefficient & $.212^{*}$ & 1.000 & $.611^{* *}$ & $.463^{* *}$ \\
\hline & Sig. (2-tailed) & .034 & . & .000 & .000 \\
\hline & $\mathrm{N}$ & 100 & 100 & 100 & 100 \\
\hline & Correlation Coefficient & $.266^{* *}$ & $.611^{* *}$ & 1.000 & $.574^{* *}$ \\
\hline \multirow[t]{3}{*}{ CAPABILITY } & Sig. (2-tailed) & .008 & .000 & . & .000 \\
\hline & $\mathrm{N}$ & 100 & 100 & 100 & 100 \\
\hline & Correlation Coefficient & $.518^{* *}$ & $.463^{* *}$ & $.574^{* *}$ & 1.000 \\
\hline \multirow[t]{2}{*}{ RATIONALIZATION } & Sig. (2-tailed) & .000 & .000 & .000 & . \\
\hline & $\mathrm{N}$ & 100 & 100 & 100 & 100 \\
\hline
\end{tabular}

*. Correlation is significant at the 0.05 level (2-tailed).

**. Correlation is significant at the 0.01 level (2-tailed).

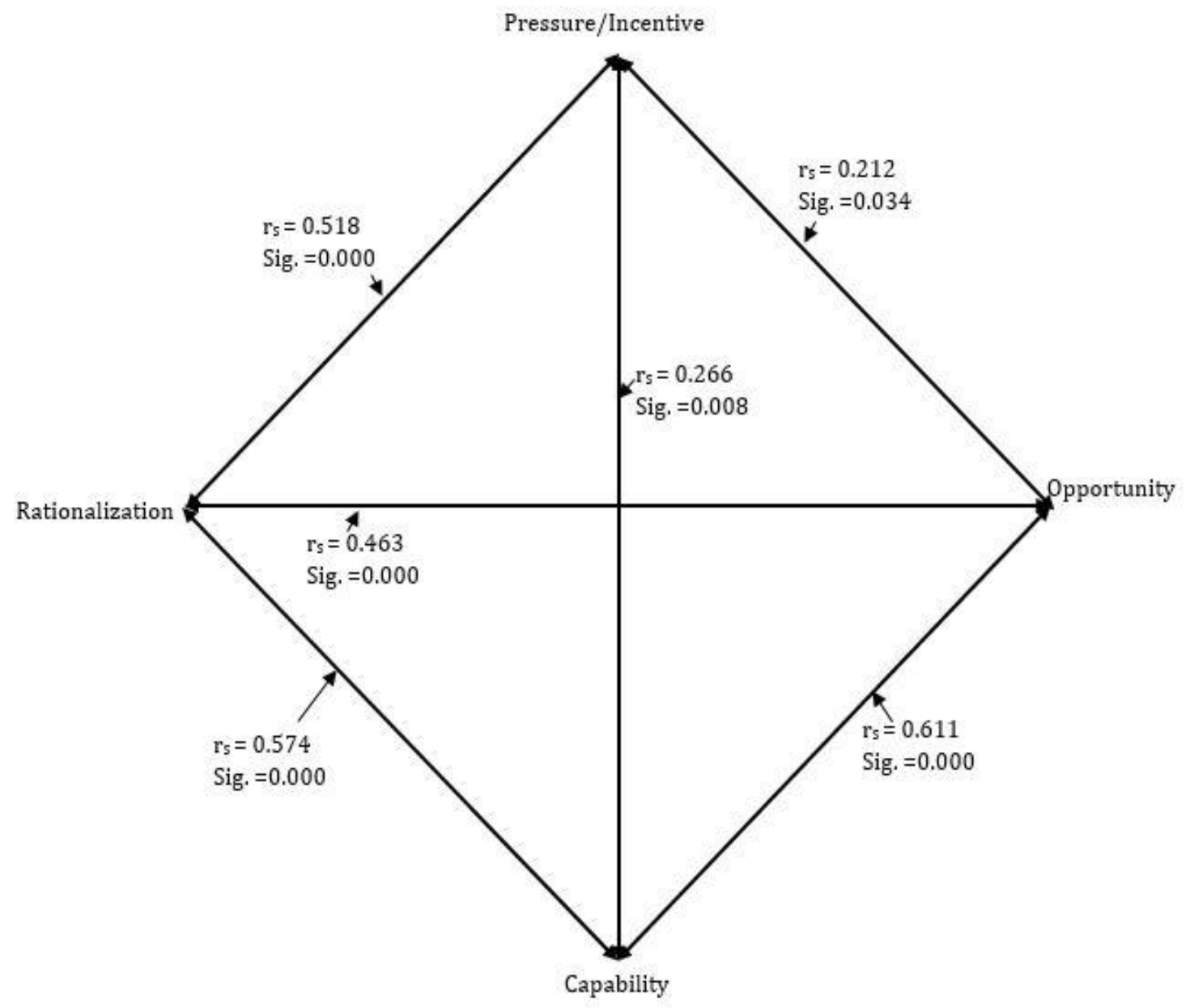

Correlation is significant at the 0.05 level ( 2 tailed)

Figure 2. The Probability/Ranking of Accountants on the Fraud Diamond Theory's Elements 
Table 3. Fraud Diamond Theory Elements Predictive Rank

\begin{tabular}{|c|c|c|c|}
\hline $\begin{array}{l}\text { Spearman rank order } \\
\text { correlation }\end{array}$ & Interpretation & $\begin{array}{l}\text { Fraud Diamond Theory Elements Predictive } \\
\text { Rank }\end{array}$ & $\begin{array}{l}\text { Significance } \\
\text { Level }\end{array}$ \\
\hline$r=0.10$ to 0.29 & Small & $\begin{array}{l}\text { Capability/Pressure } 0.266 \text { Pressure/Opportunity } \\
0.212\end{array}$ & Significant \\
\hline$r=0.30$ to 0.49 & Medium & Opportunity/Rationalization 0.463 & Significant \\
\hline$r=0.50$ to 1.0 & Large & $\begin{array}{l}\text { Capability/Opportunity } 0.611 \\
\text { Capability/Rationalization } 0.574 \\
\text { Pressure/Rationalization } 0.518\end{array}$ & Significant \\
\hline
\end{tabular}

In arranging the relationships from the positive large to small, the results showed the following order: Capability/Opportunity 0.611, Capability/Rationalization 0.574, Pressure/Rationalization 0.518, Opportunity/Rationalization 0.463 , Capability/Pressure 0.266 and Pressure/Opportunity 0.212 . The positive relationship between the elements of the fraud diamond theory implies owners, directors, managers, and supervisors of businesses. The results imply that from the viewpoint of accountants, capability relationship with opportunity and rationalization are the most critical or large indicators for fraud to happen whereas capability relationship with pressure and opportunity relationship with pressure give the small indication of fraud happening.

The ranking of Capability/Opportunity as the highest implies that when the opportunity is controlled or minimized, the capability of potential fraudsters can be rendered redundant. It is because the capability of people to commit fraud can hardly be removed. However, when there is no opportunity to utilize their capability, fraud can scarcely be perpetuated. More so, the ranking of capability/rationalization as the second highest means that when potential fraudsters cannot conceal or justify why a fraud must be committed, they delay or avoid committing such acts.

A very critical point out of this research is the element of capability as its combinations to all the other fraud elements predict more significant effects. This paper proposes effective supervision as the way to control or minimize the impact of an employee using its capability to commit fraud. According to Hamberg (2013), whereas auditing highlights financial controls, supervision checks employees' competence, operational quality, and clients' results. Effective supervision instills standards and blocks loopholes in systems and coordinates activities based on design. Further, supervision must be unpredicted oversight mutuality that is backed by hard disciplinary action (Hood et al., 1999). It must be the ultimate aim of directors to set the standards, supervisors who are detectors and effectors to gather information and cause behavioral change respectively (Hamberg 2013).

These research findings corroborate the findings of Omar and Mohamad (2010) in which external and internal auditors' respectively ranked capability and opportunity as the highest factor for committing fraud. Enofe et al. (2016) also ranked capability highest. Contrary, Asare et al. (2016) ranked rationalization highest. The probable ranking shape of fraud diamond theory is shown in figure 2.

\section{Conclusions and Recommendations}

This study has concluded that there is a positive linear relationship among all the four elements of fraud diamond theory. Though the relationship strength that exists is only for prediction and must not be assumed as causative, it can inform policy decisions and the early detection of fraud. Accountant's predictive rank for early detection of fraud is to find solutions to the occurrences of Capability/ Opportunity, Capability/Rationalization, Pressure/Rationalization, Opportunity/Rationalization, Capability/ Pressure and Pressure/Opportunity relationships.

The positive relationship between the elements of the fraud diamond theory has implications for owners, directors, managers, and supervisors of the business and therefore must pay attention to each the relationship between the diamond fraud theory in formulating policies and establishing internal controls.

When the opportunity is minimized, potential fraudsters' capability can be rendered redundant through supervision. Moreover, when rationalization is made difficult, potential fraudsters delay or avoid their act of fraud. Policy-makers should, therefore, consider policies that reduce the opportunity to commit fraud. Rationalization should also be given much attention. Effective supervision must be intensified to 
control capability. We recommend that further research must be conducted in various fields of industry and among professions to know how they will rank a predictive relationship model for the early detection of fraud based on the fraud diamond theory.

\section{References}

1. Abdullahi, R., Mansor, N., \& Nuhu, M. S. (2015). Fraud triangle theory and fraud diamond theory. Understanding the convergent and divergent for future research. International Journal of Academic Research in Accounting, Finance and Management Science, 5(4), 38-45. Doi: org/10.6007/IJARAFMS/v5$13 / 1823$

2. Asare, S. K., Wright, A., \& Zimbelman, M. F. (2017). Challenges facing auditors in detecting financial statement fraud: insight from fraud investigations. Journal of Forensic \& Investigative Accounting, 7(2), 63-112.

3. Cohen, J. (1988).Statistical power analysis for the behavioral sciences. (2nd ed.). Hillsdale, NJ: Erlbaum.

4. Cressey, D. R. (1953). Other people's money. Montclair, NJ: Patterson Smith, 1-300.

5. Dorminey, J. W., Fleming, A. S., Kranacher, M., \& Riley, R. A. (2010). Beyond the fraud triangle: Enhancing deterrence of economic crimes. The CPA Journal, 80(7), 17-24.

6. Enofe, A. O., Egbe, M.E., \& America, D. O. (2016). Internal control mechanism and fraud prevention in Nigeria public sector: An application of the new fraud diamond theory. Journal of Accounting and Financial Management, 2(1), 35-47.

7. Gbegi, D. O. \& Adebisi, J.F (2013). The new fraud diamond model- how can it help forensic accountants in fraud investigation in Nigeria? European Journal Accounting Auditing and Finance Research, 1(4), 129-138.

8. Gilbert (1997). Law dictionary. Harcourt Brace Legal and Professional Publications.

9. Hamberg, E. (2013), Supervision as control system: the design of supervision as a regulatory instrument in the social services sector in Sweden. Scandinavian Journal of Public Administration, 17(3), 4564.

10. Hauke J. \& Kossowski T. (2011).Comparison of values of Pearson's and Spearman's correlation coefficient on the same sets of data. Quaestiones Geographicae, 30(2), 87-93.

11. Holtfreter, K. (2004). Fraud in organization: An examination of control mechanism. Journal of Financial Crime, 12(1), 88-95.

12.Hood, Christopher; Oliver, James; Scott, Colin; Travers, Tony (1999) Regulation inside government: waste-watchers, quality police, and sleaze-busterz. Oxford: Oxford University Press.

13.Huber, D. (2017). Forensic accounting, fraud theory and the end of fraud triangle. Journal of Theoretical Accounting Research, 12(2), 28-48.

14.Kennedy, K. A. (2012). An analysis of fraud: causes, prevention, and notable cases. Honors these and capstones 100. Retrieved from: http://Scholars.unh.edu/honors/100

15.Kung, J. E.B., Apolinar, J.M., Ramirez, J. I. \& Rebadomia, W. (2015). Developing a fraud prediction model: Application of artificial intelligence methods using firm specific data and locational factors. Asia Pacific Business \& Economics Perspectives, 3(2), 97-114.

16. Mackevicius, J. \& Giriunas, L. (2013). Transformational research of the fraud triangle. Ekonomika, 92(4), 151-163.

17.Mohamed, Y. K., Ahmad, K. A. H., \& Jon, S. (2015). Fraudulent financial reporting: An application of fraud models to Malaysian public listed companies. Macrotheme Review, 4(3), 126 -146.

18.Nijenhuis, R. (2016). Preventive of Dutch fraud cases. A multiple case study on the effectiveness of internal control in the process of financial statement fraud prevention. Retrieved from: http://essay.utwente.nl/69819/1/Nijenhuis_MA_BMS.pdf.

19.Ocansey, E. O. N. D. (2017). Forensic accounting and the combating of economic and financial crimes in Ghana. European Scientific Journal, 13(31), 379-393. Available at http://dx.doi. org/10.19044/esj.2017.v13n31p379. 
20.Ocansey, E. O. N. D., \& Ganu, J. (2017). The role of corporate culture in managing occupational fraud. Research Journal of Finance and Accounting, 8(24), 102-107.

21. Ocansey, E. O. N. D., Adegbie, F. F., \& Dada, S. O. (2015). Impact of economic and financial crimes on the economy of Ghana. VVU Journal of Business Research, 1(1), 106-121.

22.Omar, N. B., \& Mohamad Din, H. F. (2010). Fraud diamond risk indicator: An assessment of its importance and usage. In CSSR 2010 - 2010 International Conference on Science and Social Research, 607612. [5773853] DOI: $10.1109 /$ CSSR.2010.5773853

23.Popoola, O. M. J., Che-Ahmed, A. B., Samsudin, R. S., \& Salleh, K. (2016). Accountants' capability requirement for fraud prevention and detection in Nigeria. International Journal of Economics and Financial Issues, 6(54), 1-10.

24.Puspasari, N. (2016). Fraud theory evolution and its relevance to fraud prevention in the village government in Indonesia. Asia Pacific Fraud Journal, 1(2), 177-188; DOI: 10.21532apfj. 001.16.01.0215.

25.Rasha, K., \& Andrews H. (2012). The new fraud triangle. Journal of Emerging Trends in Economics and Management Sciences, 3(3).

26.Rebekic, A., Loncaric, Z., Petrovic, S., \& Maric, S. (2015). Pearson's or Spearman's correlation coefficient - which one to use? Poljoprivreda, 21(2), 47-54. DOI:dx.doi.org/10.18047/ poljo.21.2.8.

27.Ruankaew, T. (2016). Beyond the fraud diamond. International Journal of Business Management and Economic Research, 71(1), 474-476.

28.Shelton, A. M. (2014).Analysis of capabilities attributed to the fraud diamond. Undergraduate Honors Theses. Paper 213. Retrieved from: http://dc.etsu.edu/honors/213.

29.Skousen, C. J., \& Wrigt, C. J. (2006). Contemporaneous risk factors and the prediction of financial statement fraud. Retrieved from: https://ssrn.com/abstract=938736, dx.doi. org/10.2139/ssrn.938736.

30.Stephen, J. F. (1883). A history of the criminal law of England. Vols. I-III, Macmillan and Co.

31.Tsegba, I. N., \& Upaa, J. U. (2015). Consequences of financial statement fraud: A developing country perspective. International Journal of Business and Management, 10(8), 115-126. DOI:10.5539/ijbm.v10n8p115.

32. Wolfe, D., \& Hermanson, D. R. (2004). The fraud diamond considering four elements of fraud. The CPA Journal, 74(12), 38-42.

33.Wong, S. \& Venkatraman, S. (2015). Financial accounting fraud detection using business intelligence. Asian Economic and Financial Review, 5(11), 1187-1207.

34.Wuerges, A. F. E. \& Borba, J. A. (2013). Accounting fraud detection: is it possible to quantify undiscovered cases? Financial Assets and Investing, 2. Retrieved from: https://is.muni.cz/do/econ/ soubory/aktivity/fai/41500137/FAl2013_02_2.pdf DOI: 10.5817/FA12013-2-2.

35.Yego, K. S. (2016). The impact of fraud in banking industry: A case of standard chartered bank. Degree of Master in Business Administration. United State International University. Retrieved from http://erepo.usiu.ac.ke/bitstream/handle/11732/2488/The\%20Impact\%.20of\%20Fraud\%20in\%20the\%20B anking\%20Industry.pdf?sequence $=1 \&$ isAllowed $=y$.

36.Zaki, N. M. (2017). The appropriateness of fraud triangle and diamond models in assessing the likelihood of fraudulent financial statement. An empirical study on firms listed in the Egyptian stock exchange. International Journal of Social Science and Economic Research, 2(2), 2404-2433. 